\title{
Demonstration of spirochaetes in patients with Lyme disease with a modified silver stain
}

\author{
J. DE KONING, R. B. BOSMA and J. A. A. HOOGKAMP-KORSTANJE*
}

\section{Laboratory for Public Health, Departments of Pathology and Microbiology*, Jelsumerstraat 6, 8917 EN Leeuwarden, The Netherlands}

\begin{abstract}
Summary. Spirochaetes were demonstrated in material from patients with Lyme disease by short-time high-concentrate silver impregnation after treatment with amylase. Removal of mucoid material was essential to visualise Borrelia burgdorferi. Lyme spirochaetes were demonstrated in material from 23 patients with Lyme disease-erythema chronicum migrans (ECM) 10, lymphadenosis benigna cutis (LABC) 7, arthritis 4 and Bannwarth's syndrome 2. Spirochaetes were localised in the subepidermal zone, peri- and intravascularly, and in collagen fibres in ECM and LABC, and beneath the synovial lining cells in arthritis, producing marked vascular changes with fibrosis and synovial hyperplasia. Spirochaetes were also demonstrated in CSF from a patient with Bannwarth's syndrome.
\end{abstract}

\section{Introduction}

Dark-field microscopy of fresh material and silver impregnation of fresh or fixed preparations are techniques routinely employed for the demonstration of spirochaetes in tissue. The latter may produce false negative results when organisms are sparse or, as with Treponema pallidum, masked by large amounts of mucoid material (Wos and Wicher, 1985). Misidentification of fibrils, or extrusions from cells, as spirochaetes may produce false positive results.

A modification of the silver stain according to the method of Steiner (1950) producing better contrast without background interference has been evaluated for the demonstration of spirochaetes in various specimens of material from patients with Lyme disease.

\section{Materials and methods}

\section{Controls}

Samples of liver tissue from hamsters infected with Leptospira icterohaemorrhagiae serotype copenhageni and L. canicola serotype canicola (Dr Terpstra, Tropical Institute, University of Amsterdam), testicular tissue of rabbits infected with $T$. pallidum Nichols' strain (Dr van Eyk, National Institute of Public Health, Bilthoven), a lymph node containing $T$. pallidum from a patient with serologically proven syphilis (Laboratory of Public Health, Leeuwarden), a culture of Borrelia burgdorferi

Received 7 Apr. 1986; accepted 21 Jul. 1986. and three skin biopsies from patients with erythema chronicum migrans (ECM, 2) and lymphadenosis benigna cutis $(\mathrm{LABC}, 1)$ were used as positive bacteriological controls. Lyme disease was diagnosed in the latter three patients by clinical, histological and serological criteria (Professor A. Steere, Yale University, New Haven, USA; Dr B. Wilske, Max von Pettenkofer Institüt, Munich, West Germany). Biopsies of lesions from patients with eczema (5), granuloma annulare (10), erythema annulare centrifugum (3), malignant lymphoma (5) and traumatic bursitis (5), and synovial sections from patients with rheumatoid arthritis (7) were negative controls.

\section{Patients}

Specimens from 20 patients thought to have Lyme disease were studied for the presence of spirochaetes. Included were 15 skin biopsies, four synovial sections and one cerebrospinal fluid from patients with ECM (9), LABC (6), arthritis (4) and meningo-encephalitis (1). All patients and positive controls had the clinical symptoms of Lyme disease (table). The principal diagnostic criteria of Lyme disease in patients with ECM and LABC were the specific dermatological and histological features, and evidence of a tick bite. Sera from eleven patients, among them two with arthritis, two with Bannwarth's syndrome and seven with ECM or LABC, with or without known tick bites, were examined by enzyme-linked immunosorbent assay (ELISA) by Professor A. Steere (Yale University, New Haven, USA) or by IF techniques according to the method of Wilske et al. (1984). Serum IgM and IgG titres of $\geqslant 200$ units in the ELISA were judged to be positive. Serum IgM titres of $\geqslant 32$ and IgG 
titres $\geqslant 64$ in the IF test after absorption with $T$. phagedenis sonicate and treatment with anti IgG serum (Wilske et al., 1984) were judged to be positive. IgM and IgG titres $\geqslant 1: 4$ in CSF were regarded as positive.

Significantly elevated antibody titres were found in six of seven patients with ECM and LABC (serum IgM 32128 , serum IgG $32-1024$ in the IF test), in one patient with arthritis (serum IgM 16, serum IgG 64 in the IF test), and in two patients with Bannwarth's syndrome (both: serum IgM 64 by IF, 400 units by ELISA and IgG 512 by IF, 800 units by ELISA; CSF IgM 8 and IgG 128 by IF).

\section{Histological and staining procedures}

Smears of a culture of $B$. burgdorferi grown in modified Kelly's medium (Steere et al., 1984) and of the sediment of CSF were air-dried and fixed with acetone for $10 \mathrm{~min}$. The other specimens were fixed with formalin solution $8 \% \mathrm{w} / \mathrm{v}$ in water at $22^{\circ} \mathrm{C}$ for $24 \mathrm{~h}$ and embedded in paraffin; sections of $6 \mu \mathrm{m}$ were stained. Preparations from patients with $\mathrm{LABC}$ were treated to remove the paraffin and re-embedded in plastic (EFL67, Serva, Brunschwig Chemie, Amsterdam) from which semi-thin sections $(2 \mu \mathrm{m})$ were prepared by standard histological methods and stained.

All control specimens were stained according to a modification of Warthin-Starry (Bridges and Luna, 1957) to Steiner's stain (1950) and to Bosma's modification of the Steiner stain (Bosma, 1984), called Bosma-Steiner technique. The specimens from the 20 patients were stained only by the Bosma-Steiner stain. This technique differs in two ways from the original Steiner method; (i) all preparations are incubated with amylase (Sigma, Brunschwig Chemie, Amsterdam) $1 \%$ at $37^{\circ} \mathrm{C}$ for $90 \mathrm{~min}$ to remove mucoid host substances surrounding the microorganisms, and (ii) the specimens are incubated with silver nitrate $1 \%$ solution for $2 \mathrm{~h}$ at $60^{\circ} \mathrm{C}$ instead of silver nitrate $0 \cdot 1 \%$ solution for $24 \mathrm{~h}$. All slides were examined by light microscopy at various magnifications.

\section{Results}

\section{L. icterohaemorrhagiae and L. canicola}

The liver preparations showed black leptospirae in the sinusoids and in the liver cells. They were demonstrated with all stains tested (fig. 1, upper). The background was brownish with the WarthinStarry or Steiner stain and colourless with the Bosma-Steiner stain. The leptospirae were 5-15 $\mu \mathrm{m}$ long and $0.2 \mu \mathrm{m}$ thick; their appearance was undulating and there were hooks at one or both ends.

\section{T. pallidum}

The Nichols spirochaetes in testicular tissue were demonstrated by all three stains, but they were more easily seen with the Bosma-Steiner stain because of better contrast (fig. 1, middle). Treponemes in the human lymph node were hardly visible with the Warthin-Starry and Steiner stains but easily recognised with the Bosma-Steiner stain. The treponemes were coiled and were 6-20 $\mu \mathrm{m}$ long and $0 \cdot 2 \mu \mathrm{m}$ thick.

\section{B. burgdorferi}

Lyme spirochaetes were demonstrated in all skin preparations from patients with proven Lyme disease by the Bosma-Steiner stain. By contrast, the Wharthin-Starry stain showed only undulating structures in the epidermis and subepidermal zone and spirochaetes were not seen with the Steiner stain (fig. 1, below).

Table. Clinical data on 23 patients with Lyme disease

\begin{tabular}{|c|c|c|c|c|}
\hline Disease; sex; age & $\begin{array}{l}\text { Number of } \\
\text { patients }\end{array}$ & $\begin{array}{l}\text { Known } \\
\text { tick } \\
\text { bite }\end{array}$ & Site of infection & $\begin{array}{l}\text { Serological } \\
\text { confirmation } \\
\text { (number tested) }\end{array}$ \\
\hline $\begin{array}{l}\text { Erythema chronicum migrans; } 6 \mathrm{~F}, 4 \mathrm{M} \text {; } \\
\text { age } 8-50 \text { years }\end{array}$ & 10 & 6 & $\begin{array}{l}\text { leg } 6 \text {, foot } 2 \text {, breast } 1 \text {, } \\
\text { face } 1\end{array}$ & $5(6)$ \\
\hline $\begin{array}{l}\text { Lymphadenosis benigna cutis; } 3 \mathrm{~F}, 4 \mathrm{M} \text {; } \\
\text { age } 2-70 \text { years }\end{array}$ & 7 & 2 & $\begin{array}{l}\text { ear } 3 \text {, breast } 2 \text {, neck } 1 \text {, } \\
\text { scrotum } 1\end{array}$ & $1(1)$ \\
\hline Arthritis; $2 \mathrm{~F}, 2 \mathrm{M}$; age $29-60$ years & 4 & 0 & hip 2, knee 1, elbow 1 & $1(2)$ \\
\hline $\begin{array}{l}\text { Bannwarth's syndrome after ECM; } 2 \mathrm{M} \text {, } \\
\text { age } 29,36 \text { years }\end{array}$ & 2 & 2 & $\operatorname{leg} 1$, foot 1 & $2(2)$ \\
\hline
\end{tabular}

$\mathrm{F}=$ female $\mathbf{M}=$ male. 

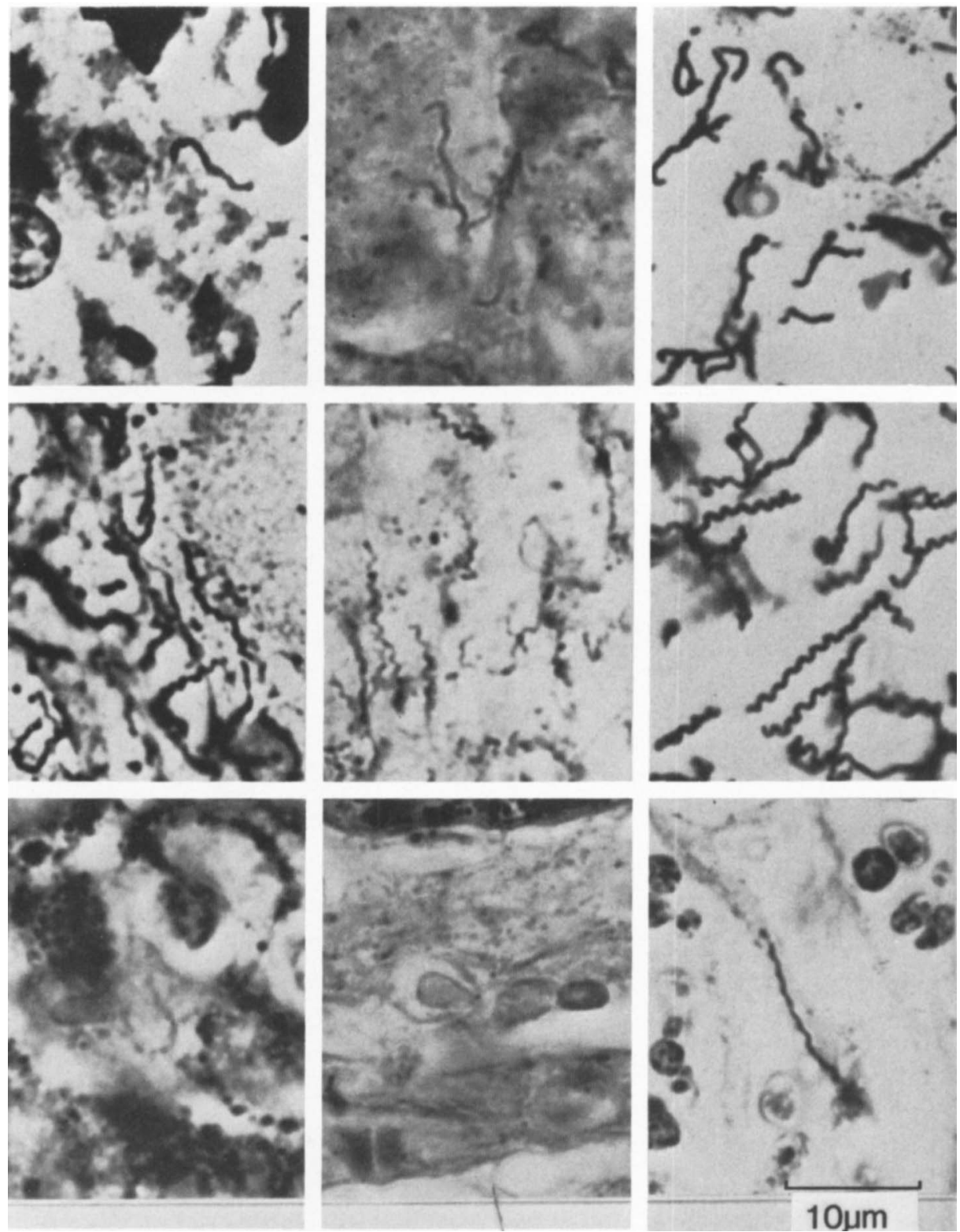

Fig. 1. Comparison of three silver stains-Warthin-Starry (left), Steiner (middle) and Bosma-Steiner (right)-for $L$. icterohaemorrhagiae in liver cells (upper), T. pallidum in testicular tissue (middle) and B. burgdorferi in skin (below); $\times 1000$.

Spirochaetes were demonstrated in all specimens from patients suspected of having Lyme disease but in none of the specimens from patients in the control group. The spirochaetes were in the central lesions of specimens from patients with ECM, in the subepidermal zone (fig. 2) and in collagen fibres. Spirochaetes in sections from patients with LABC were around and in small blood vessels and also in collagen fibres (fig. 3). Preparations of synovia from patients with arthritis showed spirochaetes lying singly (fig. 4) or in clusters around and in the small blood vessels and beneath synovial lining cells. They were not demonstrated in the synovial fluid or in the fibrinous material beneath the lining cells.

The CSF from a patient with proven Bannwarth's syndrome contained a small number of spirochaetes (fig. 5).

The borreliae in material from patients were 


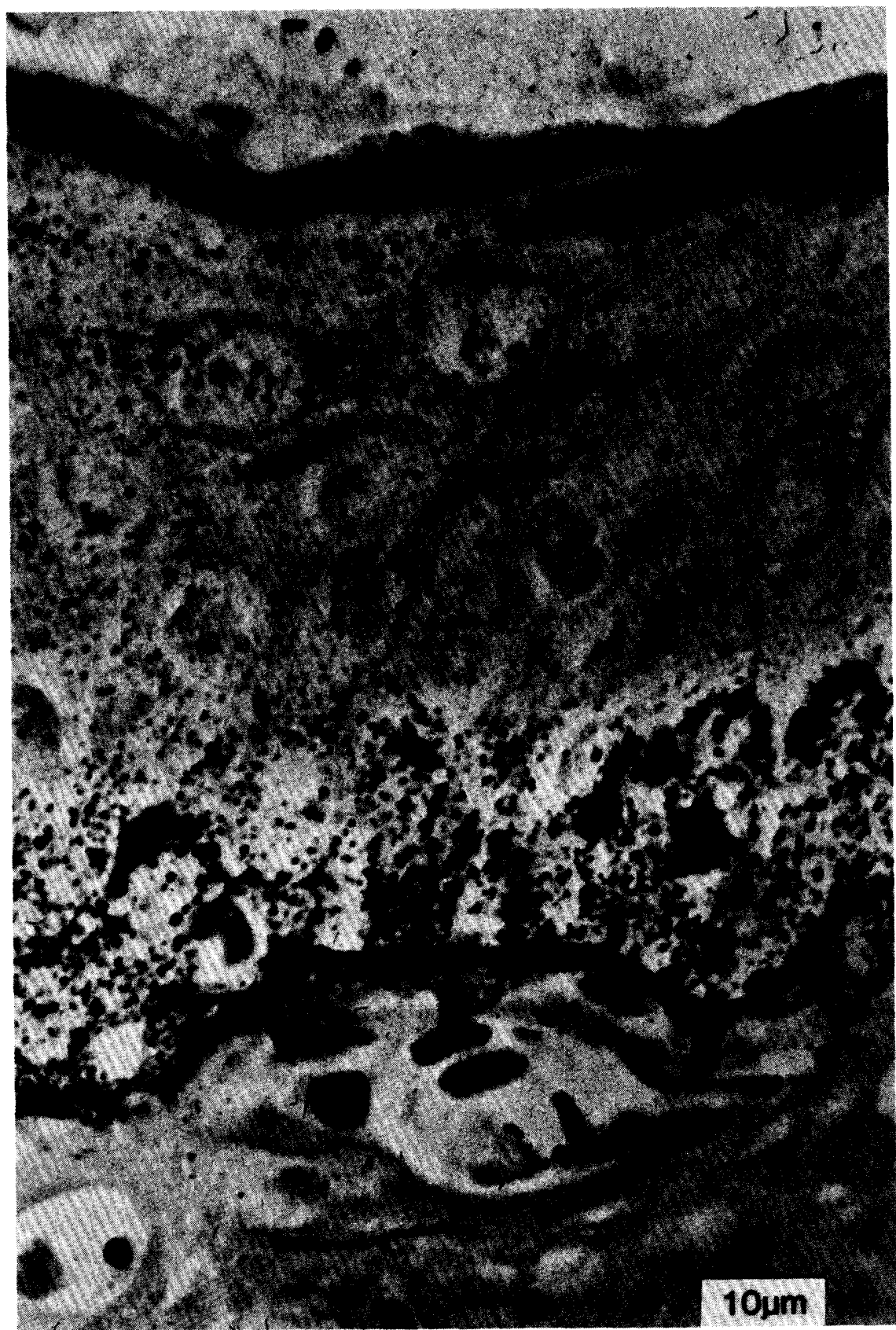

Fig. 2. Subepidermal localisation of $B$. burgdorferi in a skin preparation from a patient with ECM. Bosma-Steiner; $\times 1000$.

generally straighter and shorter than those in pure cultures. Their length was $8-30 \mu \mathrm{m}$, their thickness $0 \cdot 1-0 \cdot 2 \mu \mathrm{m}$.

\section{Discussion}

The main difficulty in staining spirochaetes with silver stains is background interference, especially in tissues with much reticulin and collagen fibres, e.g., human skin or synovia. Variation in staining time or $p \mathrm{H}$ often result in a darker background with black organisms or in a more diffuse background with less contrast. By removing interfering mucoid substances and by using a short-time high concentrate silver impregnation, the Bosma-Steiner stain clearly demarcated the black spirochaetes from an 


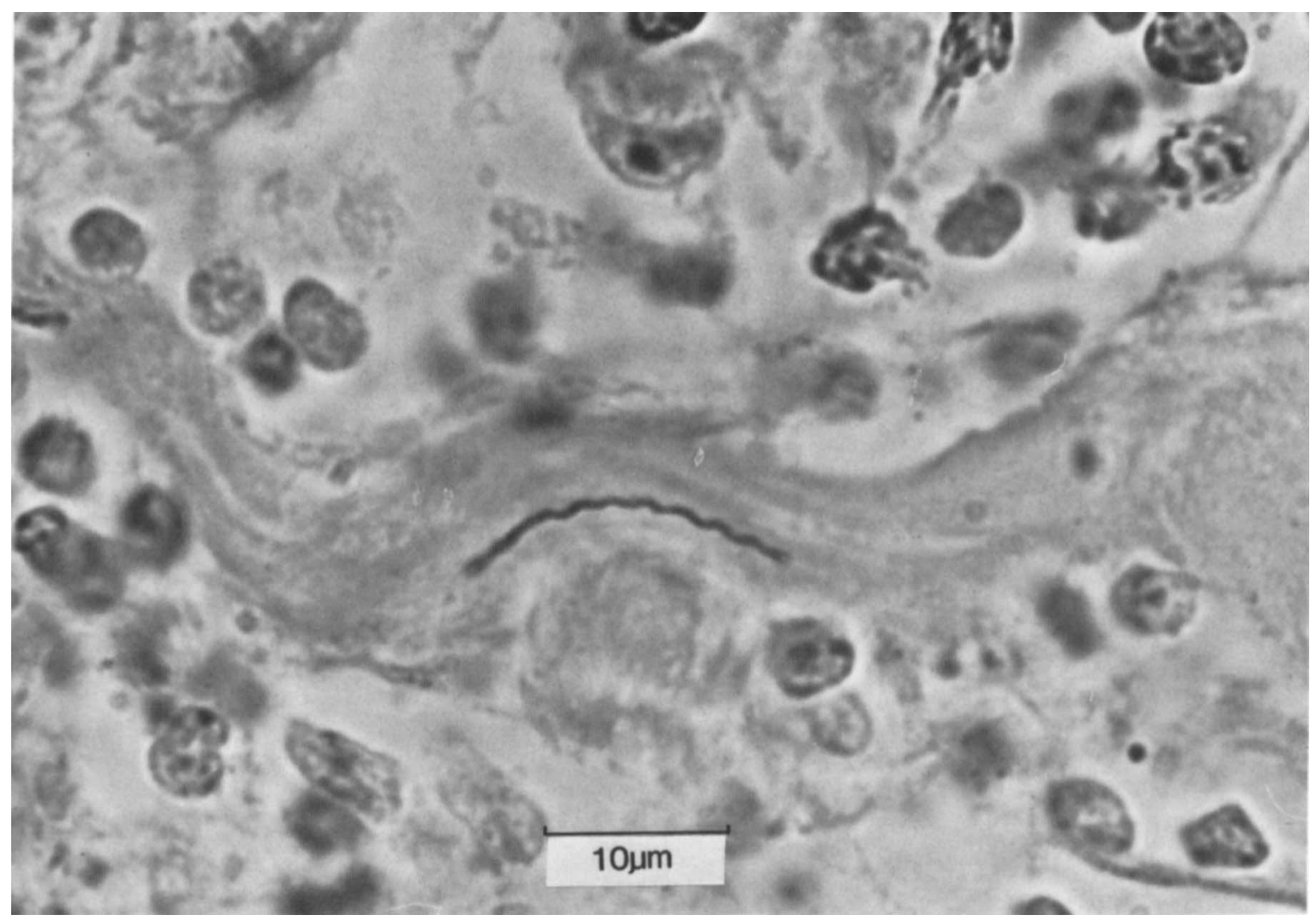

Fig. 3. B. burgdorferi in a collagen fibre of a skin preparation from a patient with LABC. Bosma-Steiner; $\times 1500$.

almost colourless background. Digestion of mucoid substances by amylase appeared to be essential for demonstration of $B$. burgdorferi. The same effect resulted from the use of hyaluronidase. This strongly suggests that the Lyme spirochaete, like $T$. pallidum. (Wos and Wicher, 1985), produces or induces the formation of mucopolysaccharides from surrounding tissues. As far as we know, this has not yet been reported for Borrelia. Better visualisation facilitated the search for organisms and enhanced morphological appearances with all spirochaetes in control material; these accorded with previous reports.

Until now, Lyme spirochaetes in material from patients have been seen only sporadically in a small percentage of preparations from patients with $\operatorname{ECM}(29 \%$; Berger et al., 1983), synovia from patients with arthritis $(25 \%$; Johnston et al., 1985) and never in CSF or biopsies from patients with LABC. We found all preparations and biopsies from the positive controls and from patients with clinical Lyme disease to be positive with the BosmaSteiner stain. Not all patients were serologically positive, but this is well known in the various stages of Lyme disease (Wilske et al., 1984).
Most spirochaetes in specimens from patients with ECM were seen at the sites where the specific inflammatory infiltrates can be demonstrated in sections stained with haematoxylin and eosin (HE) (Berger et al. 1983; Kornblatt et al. 1984)-the subepidermal zone, around and in the small blood vessels, and within the collagen fibres. The elongated, less coiled structures reported in the epidermis by Berger et al. (1983) in sections stained by Whartin-Starry stains were also present in our preparations. The atypical appearances of these spirochaetes beyond the zone of inflammation suggest that they are non-viable. The specific localisations, shape and length make the Lyme spirochaete easily distinguishable from $T$. pallidum which is localised mainly in superficial layers of the skin and not in collagen.

The number of spirochaetes in synovial sections was large in contrast to those reported with other silver stains (Johnston et al., 1985). Here also we observed most spirochaetes in the sites where inflammatory infiltrates were demonstrated in the HE stains of the same sections. In HE stains we saw chronic granulomatous inflammation (fig. 4) 


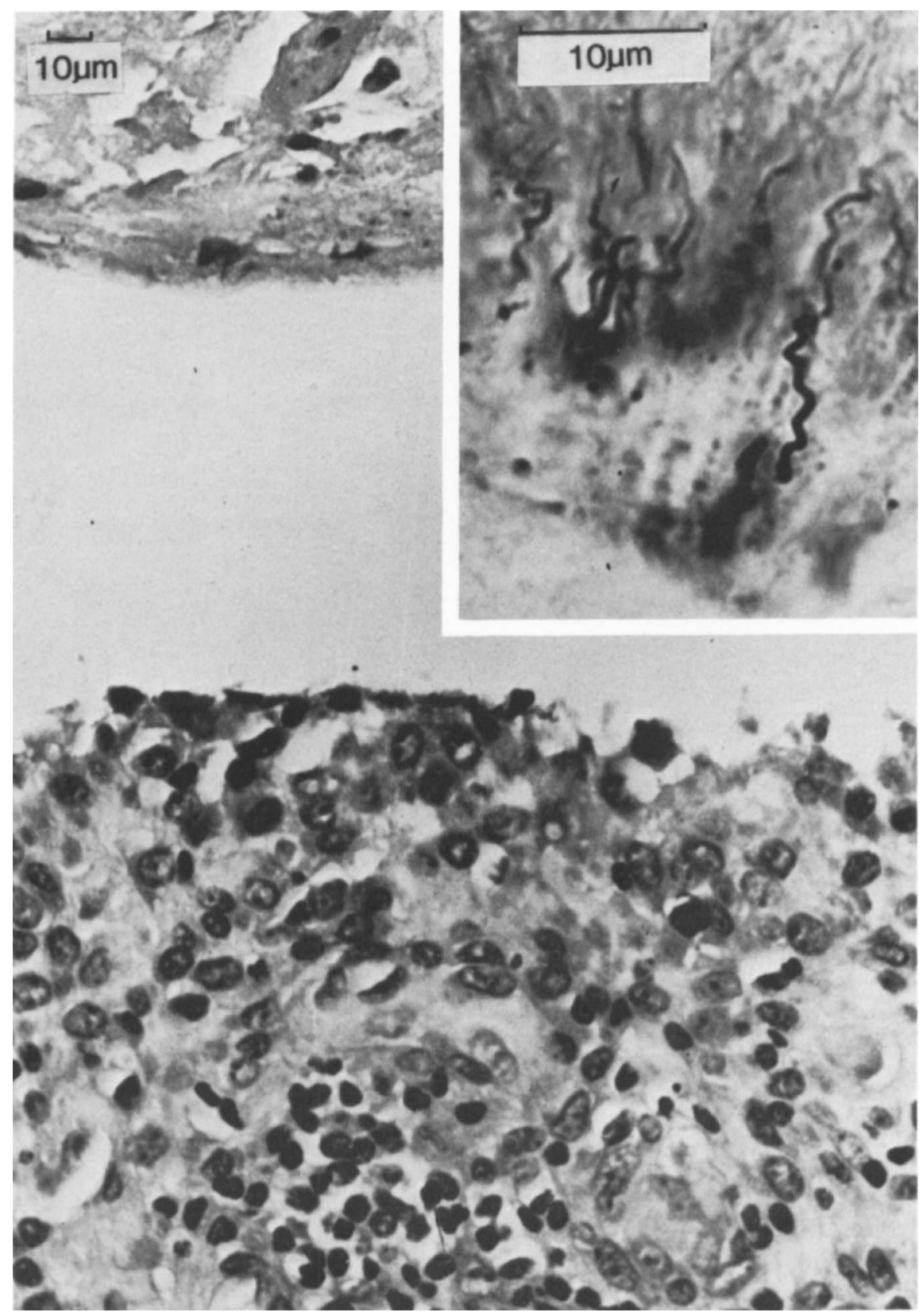

Fig. 4. Synovial section from a patient with Lyme arthritis with mononuclear infiltrate under the hyperplastic synovial lining cells and fibrinous material, retracted from the synovial cells by fixation (HE stain; $\times 300$ ). The Bosma-Steiner stain (insert; $\times 1500$ ) shows spirochaetes beneath the synovial lining cells.

with marked vascular changes (thickening of vessel cell wall), fibrosis, hyperplastic and hypertrophic synovial cells and intra-articular, fibrinous material. The synovial preparations were from patients who had had chronic arthritis for at least 6 months. The abundance of spirochaetes in synovium at that time suggests that the spirochaetes can survive for long periods and may be responsible for recurrent active infections.

Demonstration of spirochaetes in CSF by microscopy has never been reported to our knowledge. The spirochaetes found were shorter than spiro- 

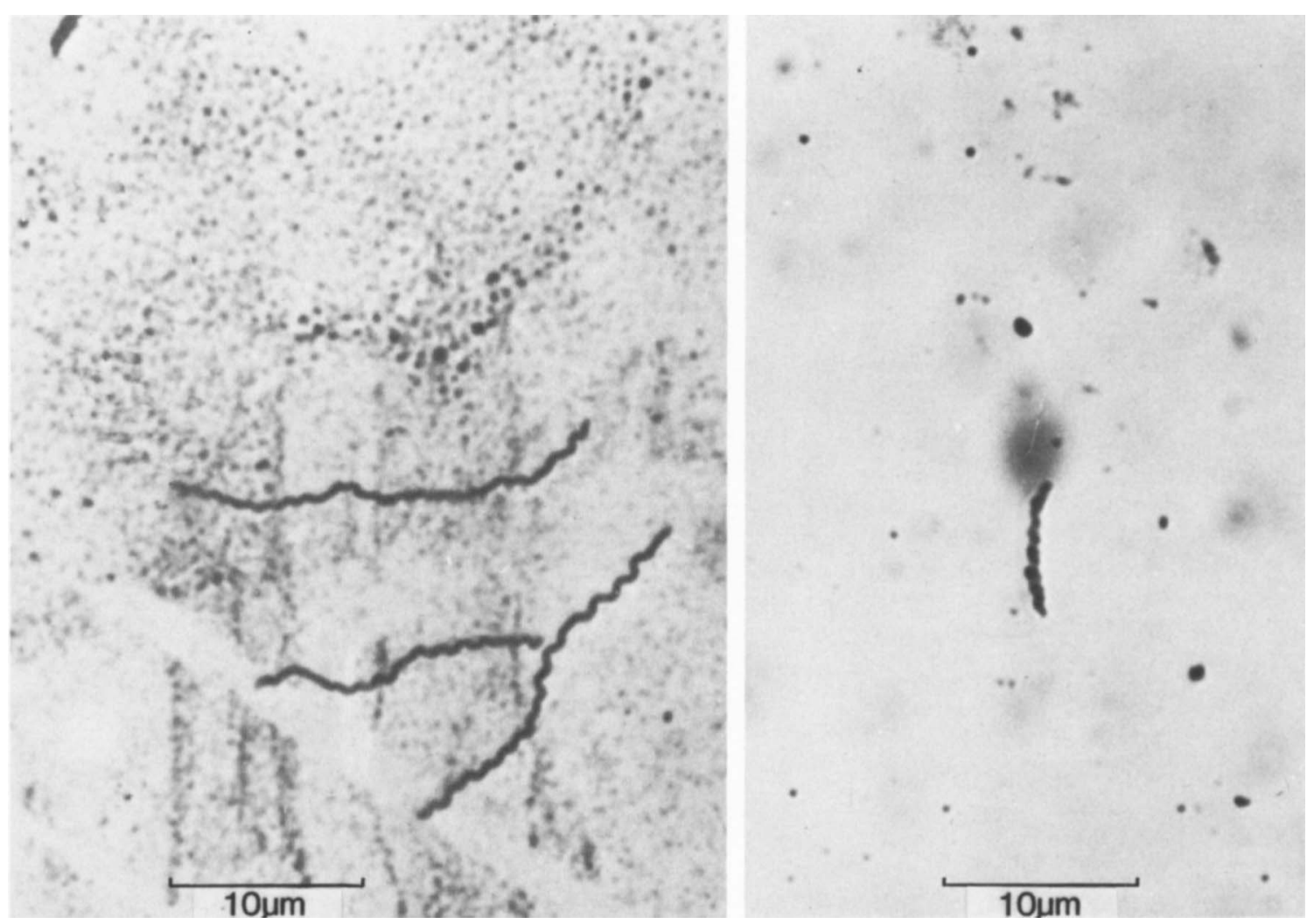

Fig. 5. Pure culture of B. burgdorferi (left) and a spirochaete in cerebrospinal fluid from a patient with Bannwarth's syndrome (right). Bosma-Steiner; $\times 1500$.

chaetes in culture but such differences between appearance in vivo and in vitro are not unusual.

Half of the patients documented in our region associated a tick bite with their disease; this conforms with reports of others (Steere et al., 1984). ECM and LABC are well-known diseases in this part of The Netherlands in summer and autumn. The local incidence of arthritis, neurological and

\section{REFERENCES}

Berger B W, Clemmensen O J, Ackerman A B 1983 Lyme disease is a spirochetosis. A review of the disease and evidence for its cause. American Journal of Dermatopathology 5: 111-124.

Bosma R B 1984 Spirochetenkleuring volgens "Gabriel Steiner". Histotechniek 5: 162-166.

Bridges C H, Luna L 1957 Kerr's improved Warthin-Starry technic. Study of the permissible variations. Laboratory Investigation 6 : 357-367.

Johnston Y E et al. 1985 Lyme arthritis spirochetes found in synovial microangiopathic lesions. American Journal of Pathology 118: 26-34. cardiological and other abnormalities is yet unknown. Direct examination of material from patients with an appropriate silver stain may help to provide such data.

We thank Professor A. C. Steere and Dr B. Wilske for helpful advice, Mr A. Groenewoud and Mr K. Koster of this laboratory for technical assistance, and Mrs D. Heeringa-Kerkstra for typing the manuscript.

Kornblatt A N, Steere A C, Brownstein D G 1984 Experimental Lyme disease in rabbits: spirochetes found in erythema migrans and blood. Infection and Immunity 46: 220-23.

Steere A C et al. 1984 The spirochetal etiology of Lyme disease. New England Journal of Medicine 308: 733-740.

Steiner G 1950 Modified silver stain of microorganisms in tissues. American Journal of Clinical Pathology 20 : 489-490.

Wilske B, Schierz G, Preac-Mursic V, Weber K, Pfister H W, Einhaupl K 1984 Serological diagnosis of erythema migrans disease and related disorders. Infection 12: 331-337.

Wos S M, Wicher K 1985 Antigenic evidence for host origin of exudative fluids in lesions of Treponema pallidum-infected rabbits. Infection and Immunity 47: 228-233. 